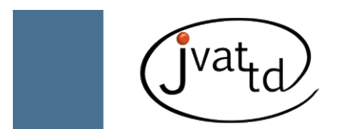

\title{
Comparison of two purified toxic fractions from Mesobuthus eupeus scorpion venom
}

Shirmardi SP (1, 2), Shamsaei M (1), Gandomkar M (2), Saniei E (1), Ghannadi M (2), Zare A (3)

(1) School of Nuclear Engineering and Physics, Amirkabir University of Technology, Tehran, Iran; (2) Nuclear Sciences and Technology Research Institute, Tehran, Iran; (3) Razi Vaccine and Serum Research Institute, Karaj, Iran.

\begin{abstract}
Iranian scorpions belong mainly to the Buthidae and Scorpionidae families, distributed into 16 genera and 25 species. In Iran, similar to other parts of the world, there are a few known species of scorpions responsible for severe envenoming; amongst which Mesobuthus eupeus is the most common. Its venom contains several toxin fractions that may affect the ion channel. In the present study purification, labeling and biological evaluation of $M$. eupeus venom are described. For separation, soluble venom was loaded on a chromatography column packed with Sephadex G-50 gel. Subsequently, the fractions were collected according to UV absorption at a wavelength of $280 \mathrm{~nm}$. Toxic fraction (F3) was loaded on an anionic ion exchanger resin and then on a cationic resin. Finally, toxic subfractions F3.1.6 and F3.1.9 were labeled with ${ }^{99 \mathrm{~m}} \mathrm{Tc}$ and injected into normal mice to distinguish excretion pathway. The venom toxic fraction was successfully obtained in its purified form. Radiolabeling of toxic fractions was performed at high specific activity with radiochemical purity of more than 97 and $95 \%$ respectively for F3.1.6 and F3.1.9. Biodistribution studies in normal mice with two toxic fractions usually show rapid clearance of the compounds from blood and tissue except for kidneys. Since tissue distribution studies are very important for clinical purpose, the present findings suggest that ${ }^{99 \mathrm{~m}} \mathrm{Tc}$ labeling of venom is a useful tool for in vivo studies and comprises an excellent approach to monitoring the process of biodistribution and kinetics of toxins.
\end{abstract}

Key words: Mesobuthus eupeus, venom, purification, chromatography, radiolabeling, biodistribution.

\section{INTRODUCTION}

Scorpions are widespread in all populated areas in Iran, both rural and urban. Iranian scorpions belong predominantly to the Buthidae and Scorpionidae families and the most common species are: Mesobuthus eupeus, Odontobuthus doriae, Scorpio maurus, and Hemiscorpius lepturus. M. eupeus, of the Buthidae family, is the most frequent scorpion species in the country (15). Its venom may provoke several symptoms from pain, inflammation and muscle paralysis to death in children. This venom is composed mainly of basic peptides and several toxin fractions that can affect the exposed fibers and the muscles directly or through motor nerves causing neuromuscular intoxication. Pharmacological characterizations of the venom and its subfractions have not yet been reported. Previously, Kadkhodaei et al. (6) isolated some toxic fractions of M. eupeus venom.

Scorpion venoms are particularly rich in small neurotoxic proteins or peptides that interact specifically with various ionic channels in excitable membrane sizes. These short-chain toxins are composed of 30 to 40 amino acid residues and are mainly cross-linked by two or four disulfide bridges that are mostly active on $\mathrm{K}^{+}$or $\mathrm{Cl}^{-}$and $\mathrm{Ca}^{2+}$ channels (7-9). In such groups we can find a short toxin with four disulfide bonds called chlorotoxin, a chloride-channel blocking toxin extracted from the scorpion Leiurus quinquestriatus (10-12). The toxins that 
act on $\mathrm{Na}^{+}$channels consist of 60 to 70 amino acid residues and four intermolecular disulfide bonds.

To date, about 400 toxic peptides have been identified in scorpion venoms, mainly among those of the Buthidae family. The main focus has been placed on the Buthidae family because some species within this family possess particularly potent venoms that are harmful to humans (1-6, $8)$. Knowing the biodistribution of their venom is helpful for development of potent antivenoms for clinical use.

Radionuclide labeling is an interesting approach for observing the distribution and concentration in organs of an unknown compound. Technetium-99m $\left({ }^{99 \mathrm{~m}} \mathrm{Tc}\right)$ remains at the forefront of such investigations due to its ideal nuclear characteristics (6-hour half-life and gamma energy of $140 \mathrm{keV}$ ), ready availability from a ${ }^{99} \mathrm{Mo}$ (molybdenum-99)/ ${ }^{99 \mathrm{~m}} \mathrm{Tc}$ generator, and well-established labeling chemistries (13).

In the present study, preparation, purification and labeling of Iranian Mesobuthus eupeus (IMe) venom were performed so that the biological behavior of the labeled compound was evaluated in normal mice through biodistribution assay.

\section{MATERIALS AND METHODS}

\section{Materials}

All chemicals were purchased from Sigma and Fluka (Germany). ${ }^{99 \mathrm{~m} T c}$ radionuclide was extracted from a ${ }^{99} \mathrm{Mo} /{ }^{99 m} \mathrm{Tc}$ generator at the Iran Atomic Energy Organization.

\section{Experimental Animals}

Animal studies were performed in compliance with the regulations of the Nuclear Sciences and Technology Research Institute (NSTRI), and with generally accepted guidelines governing such works. For this aim, normal male mice, weighing between 25 and $30 \mathrm{~g}$ were injected with venom and investigated.

\section{Venom preparation}

Crude venom of IMe was obtained from Iranian Mesobuthus eupeus scorpion. The scorpions were collected with UV light at night from different parts of the country and were milked by electric stimulation at the end of tail. The venom was dialyzed and stored at $-20^{\circ} \mathrm{C}$. The freeze-dried venom (180 mg) was dissolved in distilled water and then dialyzed against distilled water at $4^{\circ} \mathrm{C}$ for
48 hours. After dialysis, the venom solution was centrifuged (Sigma $6 \mathrm{~K} 15^{\circledR}$, UK) at $14,000 \mathrm{rpm}$ for 17 minutes and the supernatant was collected.

\section{Venom Purification Process \\ Gel filtration on Sephadex G-50}

Lyophilized crude venom (180 mg) was dissolved in ammonium acetate buffer $(\mathrm{pH}$ 8.6) and the insoluble material was removed by centrifugation and filtration (e.g. mucoproteins). Supernatant was applied to a column of Sephadex G-50 $(2.5 \times 125 \mathrm{~cm})$ equilibrated with $0.1 \mathrm{M}$ ammonium acetate buffer ( $\mathrm{pH}$ 8.6). The elution was carried out with the same buffer at a flow rate of $60 \mathrm{~mL} /$ hour. Volumes of $10 \mathrm{~mL}$ were collected and each fraction was identified by UV spectrophotometer $(280 \mathrm{~nm})$, mixed and lyophilized.

\section{Anion-exchange chromatography}

Diethylaminoethyl (DEAE) column (1.5 x $25.0 \mathrm{~cm}$ ) was equilibrated with $0.02 \mathrm{M}$ Tris base buffer ( $\mathrm{pH}$ 8.3). Fraction 3 (F3), previously found to be toxic, was dialyzed and condensed with polyethylene glycol (PEG) and applied to the column. The elution was carried out with a linear gradient from $0.0 \mathrm{M}$ to $0.5 \mathrm{M}$ sodium chloride in buffer at a flow rate of $20 \mathrm{~mL} /$ hour. Volumes of 5 $\mathrm{mL}$ were collected and all volumes corresponding to each fraction were mixed and lyophilized.

\section{Cation-exchange chromatography}

Carboxymethyl $(\mathrm{CM})$ column $(1.5 \times 25.0 \mathrm{~cm})$ was equilibrated with $0.02 \mathrm{M}$ sodium acetate buffer ( $\mathrm{pH} 4.8$ ). Fraction 3.1 (F3.1) which was toxic from the previous stage was dialyzed and condensed with PEG and applied to the column. The elution was carried out with a linear gradient of sodium chloride from $0.0 \mathrm{M}$ to $0.5 \mathrm{M}$ in a buffer at a flow rate of $20 \mathrm{~mL} /$ hour. Volumes of 5 $\mathrm{mL}$ were collected and all volumes corresponding to each fraction were mixed and lyophilized.

\section{Labeling with ${ }^{99 \mathrm{~m}} \mathrm{Tc}$}

The toxic purified fractions of F3.1.6 and F3.1.9 were labeled with ${ }^{99 \mathrm{~m}} \mathrm{Tc}$ using stannous chloride and sodium borohydride as reducing agents (14-16). Preliminary studies were performed to establish the optimum conditions for obtaining the highest yield of labeled venom. Briefly, stannous chloride $(4 \mu \mathrm{g})$ and sodium borohydride $(20 \mu \mathrm{g})$ were transferred to two vials containing 
lyophilized F3.1.6 (67 $\mu \mathrm{g})$ and F3.1.9 $(67 \mu \mathrm{g})$ for reduction of pertechnetate anions. The $\mathrm{pH}$ was adjusted to 7.5 with sodium hydroxide $(\mathrm{NaOH})$. $\mathrm{Na}^{99 \mathrm{~m}} \mathrm{TcO}_{4}$ [3.7 MBq (Bq: becquerel)] freshly eluted from a ${ }^{99} \mathrm{Mo} /{ }^{99 \mathrm{~m}} \mathrm{Tc}$ generator was added to the reaction vials $(1.85 \mathrm{MBq}$ for each vial). The mixtures were incubated for 20 minutes at room temperature under vacuum conditions. After this period, $1 \mathrm{~mL}$ of saline solution was added to reaction vials $(0.5 \mathrm{~mL}$ in each vial) in order to interrupt the labeling reaction $(16,17)$. The scheme of direct labeling with ${ }^{99 \mathrm{~m}} \mathrm{Tc}$ is displayed in Figure1.

\section{${ }^{99 m}$ Tc-Venom Stability}

The stability of labeled F3.1.6 and F3.1.9 in PBS was determined by storing them at room temperature for 24 hours. ${ }^{99 \mathrm{~m}} \mathrm{Tc}$-labeled venom was characterized by instant thin-layer chromatography (ITLC) on silica gel 60 (Merck, Germany) and Whatman paper number 1 (Germany) previously saturated with $1.0 \%$ bovine serum albumin solution. As a mobile phase acetone was used for

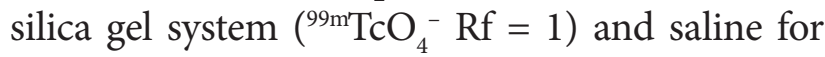
Whatman paper number $1\left({ }^{99 \mathrm{~m}} \mathrm{Tc}\right.$-colloid $\left.\mathrm{Rf}=0\right)$. The radioactivity was quantified by cutting the strip $\left(1.5 \times 10 \mathrm{~cm}^{2}\right)$ into $1-\mathrm{cm}$ pieces and counting in a well type gamma counter.

\section{Biodistribution}

Male mice were injected with a saline solution containing $0.02 \mathrm{MBq}$ of radiolabeled peptide into the tail vein. For ex vivo counting, the animals were killed after ten minutes, one and four hours and various organs were dissected, weighed and counted for radioactivity. Data were expressed as the percentage of injected dose per gram of tissue (\%ID/g).

\section{Statistical Analysis}

The calculations of means and standard deviations for internalization and biodistribution were performed on Microsoft Excel. Student's t-test was used to determine statistical significance. Values of $\mathrm{p}<0.05$ were considered statistically significant.

\section{RESULTS}

\section{Sephadex G-50 Gel Chromatography}

Total amount of protein loaded on the gel filtration column was $109 \mathrm{mg}$. After elution, four fractions were obtained by gel filtration chromatography process (F1, F2, F3 and F4).

\section{Toxicity Studies and Pharmacological Effects of Main Fractions}

In this step, two normal male mice weighing 25 to $30 \mathrm{~g}$ were injected with radiolabeled peptides for toxicity investigation $(1 \mathrm{mg}$ of protein of each fraction injected into each mouse). Fraction number 3 (F3) was found to be toxic to mice. The total protein of F3 was determined and found to be $98 \mathrm{mg}$. All obtained fractions and toxic fraction in this step are shown in Table 1 and Figure 2.

\section{Anion-Exchange Chromatography}

After elution, three fractions were obtained by anion-exchange chromatography process (F3.1, F3.2, and F3.3).

\section{Toxicity Studies and Pharmacological Effects of Subfractions}

After injection of these three fractions into mice, it was found that fraction F3.1 was toxic. All the fractions obtained in this step are displayed in Table 2 and Figure 3.

\section{Cation-Exchange Chromatography}

After loading fraction F3.1 on a cationexchange chromatography column, ten fractions
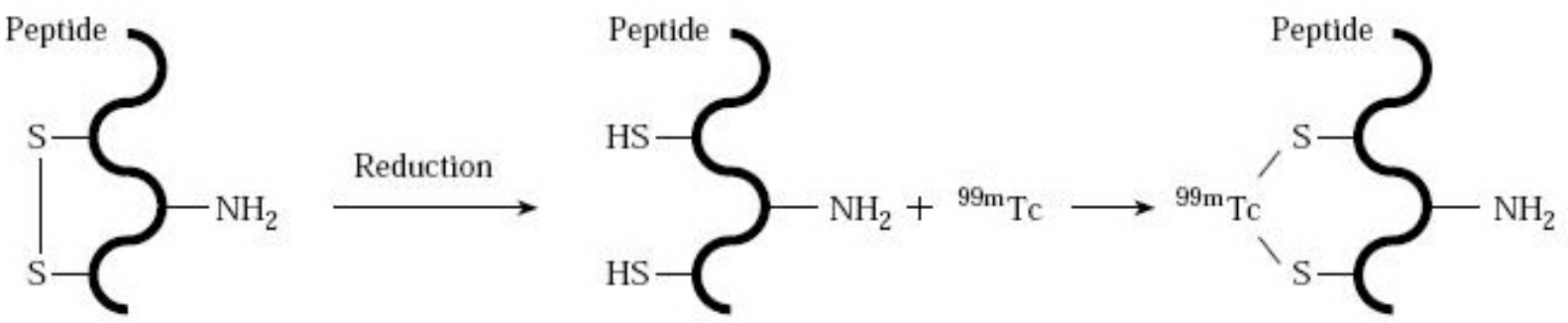

Figure1. Method for direct labeling of the venom. 
were obtained (F3.1.1, F3.1.2, F3.1.3, F3.1.4, F3.1.5, F3.1.6, F3.1.7, F3.1.8, F3.1.9 and F3.1.10).

\section{Toxicity Studies and Pharmacological Effects of Subfractions}

Each fraction was injected into two normal mice in order to observe its toxic effects. During 24 hours post-injection, the mice that received fractions F3.1.6 and F3.1.9 develop symptoms of paralysis and then died. The other fractions had no biological effects. All fractions obtained in this step are shown in Table 3 and Figure 4.

\section{Labeling}

Radiolabeling of the venom was performed at high specific activity with radiochemical purity greater than $97 \%$ and $95 \%$ respectively for F3.1.6 and F3.1.9, which was stable for more than four hours. The best condition was $67 \mu \mathrm{g}$ and 1.85 $\mathrm{MBq}$ activity. The stability of labeled F3.1.6 and F3.1.9 in PBS was respectively $16 \%$ and $18 \%$ after 24 hours.

\section{Biodistribution}

The labeled scorpion venom (fractions F3.1.6 and F3.1.9) was intravenously injected into mice $(0.02 \mathrm{MBq})$. At different time intervals, biodistribution tests in normal mice showed rapid clearance of the compound from blood and tissue except for the kidneys. The initial uptake of F3.1.6 in blood after ten minutes was $26.1 \%$, dropping to $3.8 \%$ four hours after administration, which indicates the rapid clearance of scorpion venom from the circulatory system.

Liver uptake after ten minutes was $11.3 \%$ and decreased to $6.1 \%$ after four hours. Kidney uptake of F3.1.6 was about $19.5 \%$ at ten minutes. The retention of radioactive fractions by the kidney was observed up to 4 hours (18.7\%) after the injection. The complex concentration in the stomach was almost insignificant. The maximum uptake in the intestines was $16.2 \%$ four hours post-injection. The biodistribution results for F3.1.6 fraction are displayed in Figure 5.

In blood, the initial uptake of F3.1.9 after ten minutes was $22.16 \%$ which dropped to $2.64 \%$ four hour after the administration. The initial liver uptake (ten minutes) was 9.28\% and decreased to $7.48 \%$ four hours later. In the kidneys, the uptake of F3.1.9 was about $21 \%$ at ten minutes; then, the retention of radioactive
Table1. Killing effect of venom submitted to gelfiltration chromatography using Sephadex G-50

\begin{tabular}{c|c|c}
\hline Peak & $\begin{array}{c}\text { Killing effect } \\
\text { in mouse 1 }\end{array}$ & $\begin{array}{c}\text { Killing effect } \\
\text { in mouse 2 }\end{array}$ \\
\hline F1 & - & - \\
\hline F2 & - & - \\
\hline F3 & + & + \\
\hline F4 & - & - \\
\hline
\end{tabular}

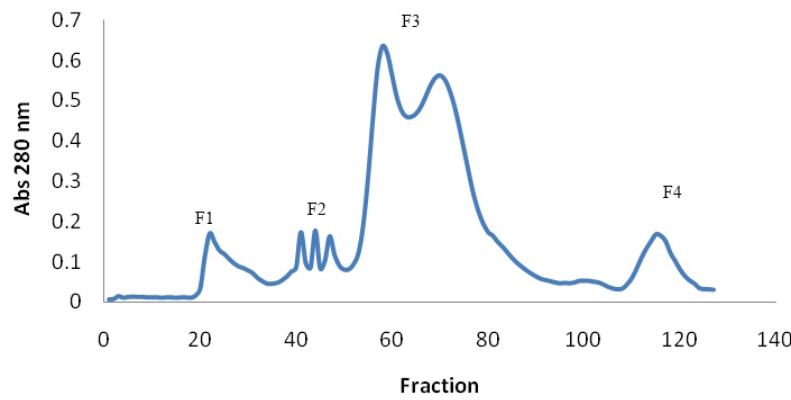

Figure 2. Separation of Mesobuthus eupeus venom by gel filtration chromatography.

Table 2. Killing effect of F3 fraction obtained by anion-exchange chromatography with DEAE resin

\begin{tabular}{c|c|c}
\hline Peak & $\begin{array}{c}\text { Killing effect } \\
\text { in mouse 1 }\end{array}$ & $\begin{array}{c}\text { Killing effect } \\
\text { in mouse 2 }\end{array}$ \\
\hline F3.1 & + & + \\
\hline F3.2 & - & - \\
\hline F3.3 & - & - \\
\hline
\end{tabular}

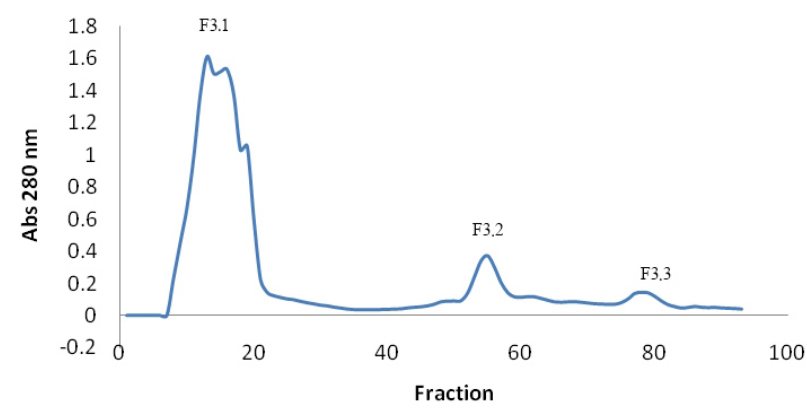

Figure 3. Fractions of $\mathrm{F} 3$ obtained by anionexchange chromatography with DEAE resin. 
Table 3. Killing effect of F3.1 fraction obtained by cation-exchange chromatography with $\mathrm{CM}$ resin

\begin{tabular}{c|c|c}
\hline Peak & $\begin{array}{c}\text { Killing effect } \\
\text { in mouse 1 }\end{array}$ & $\begin{array}{c}\text { Killing effect } \\
\text { in mouse 2 }\end{array}$ \\
\hline F3.1.1 & - & - \\
\hline F3.1.2 & - & - \\
\hline F3.1.3 & - & - \\
\hline F3.1.4 & - & - \\
\hline F3.1.5 & - & + \\
\hline F3.1.6 & + & - \\
\hline F3.1.7 & - & - \\
\hline F3.1.8 & - & + \\
\hline F3.1.9 & + & - \\
\hline F3.1.10 & - & - \\
\hline
\end{tabular}

fractions by these organs four hours later was $27 \%$. The complex concentration in the stomach was almost insignificant. The maximum uptake in the intestine was $10.46 \%$ four hours after the injection. The results of biodistribution of F3.1.9 fraction are shown in Figure 6.

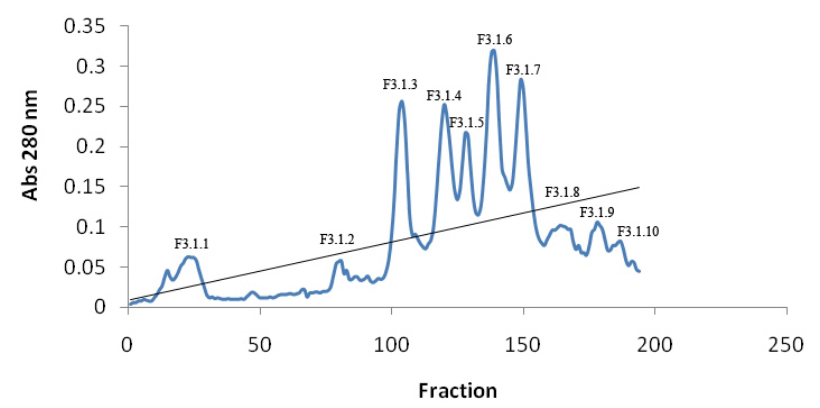

Figure 4. Fractions of F3.1 obtained by cationexchange chromatography with $\mathrm{CM}$ resin.

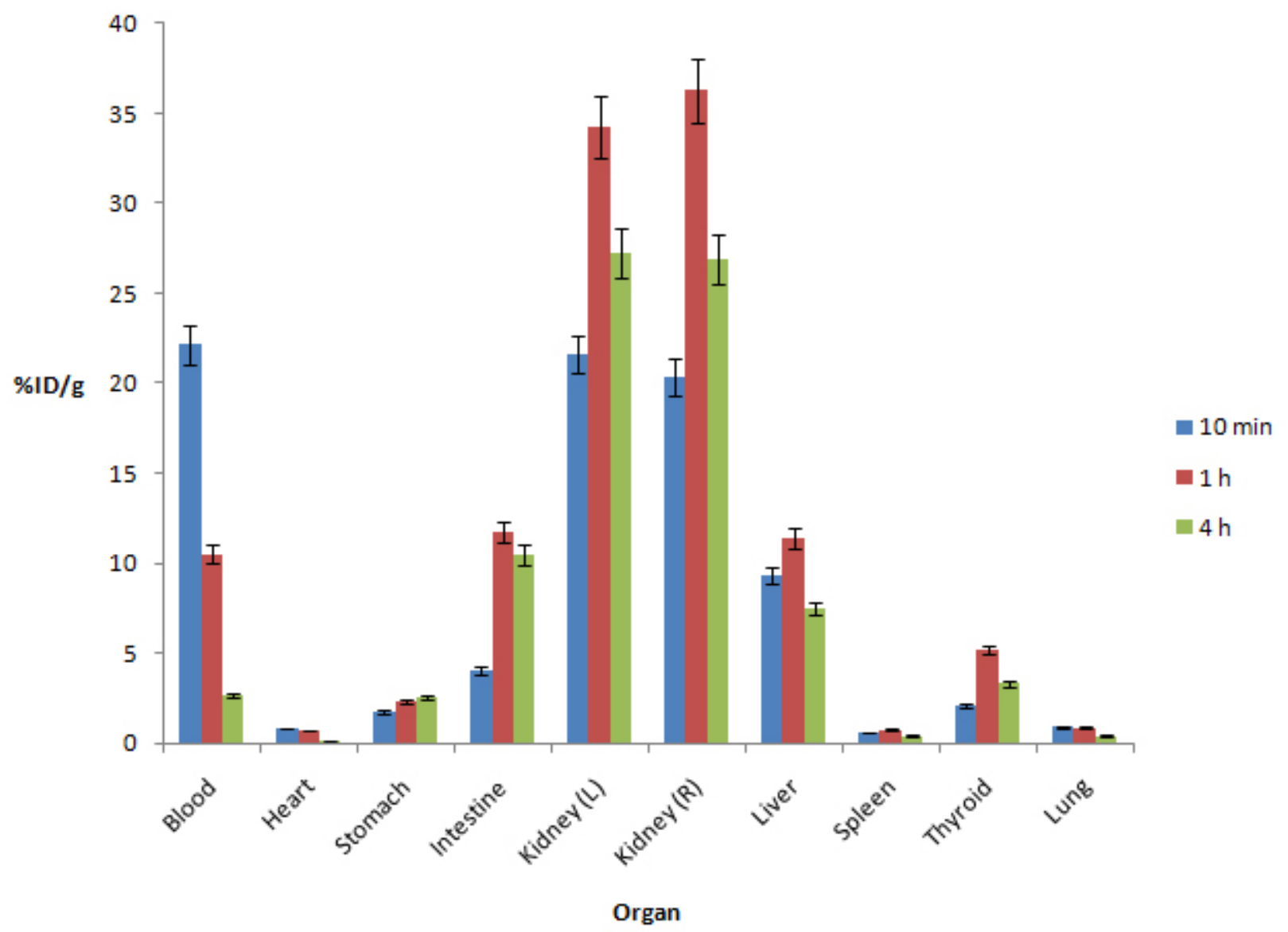

Figure 5. Biodistribution of F3.1.6 fraction in mouse assay at ten minutes, one and four hours after administration. Data are presented as $\% \mathrm{ID} / \mathrm{g} \pm \mathrm{SD}$ and results are the means of groups of three animals. Values of $p<0.05$ are considered statistically significant 


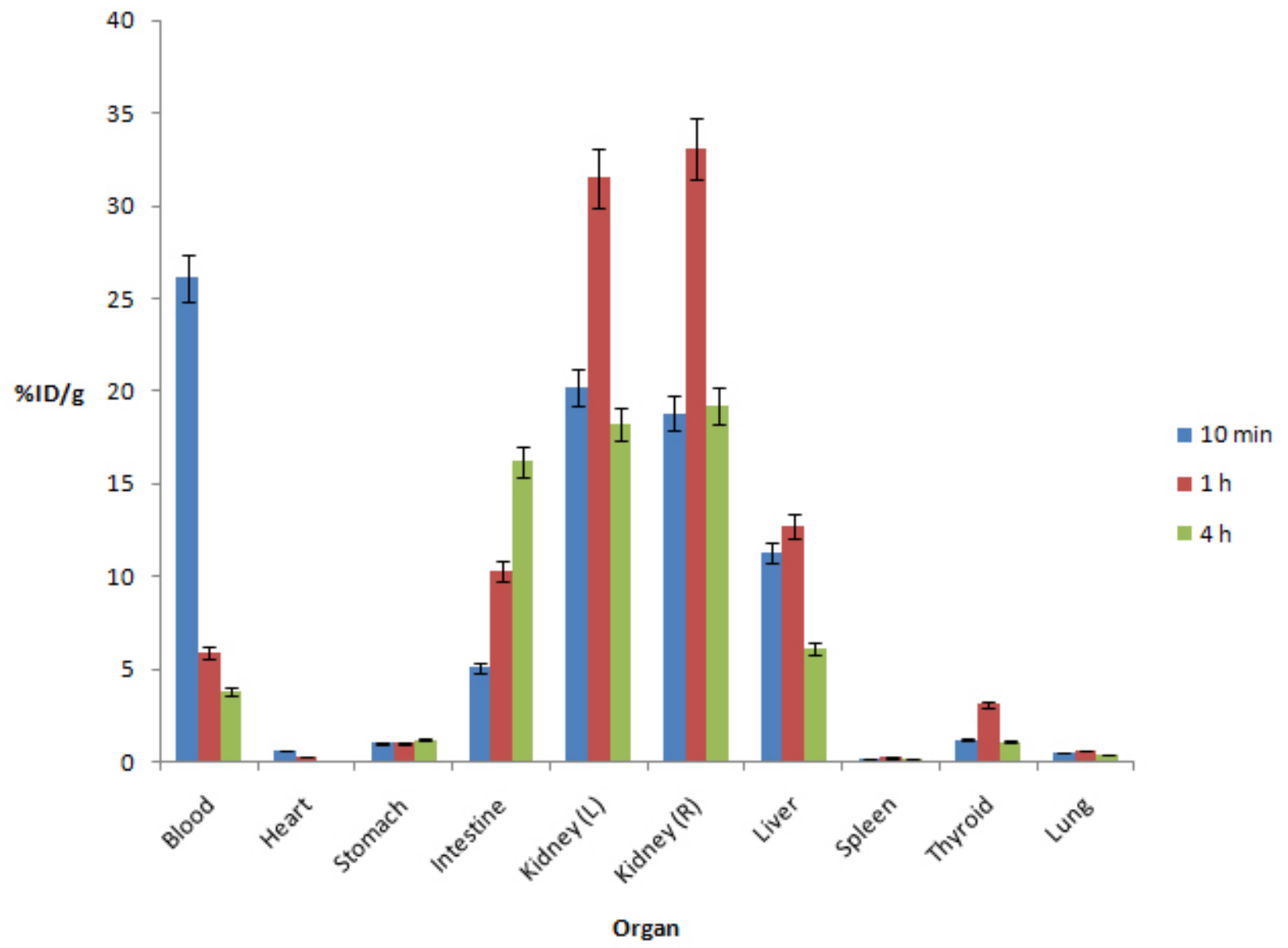

Figure 6. Biodistribution of F3.1.9 in mice at ten minutes, one and four hours. Data are presented as \%ID/g $\pm \mathrm{SD}$ and results are the means of groups of three animals. Values of $p<0.05$ are considered statistically significant

\section{DISCUSSION}

All scorpion species, including Mesobuthus eupeus, with highly potent mammal-specific neurotoxins belong to the family Buthidae that, therefore, is medically important (18). Several genera of this family - such as Tityus, Centruroides, Androctonus and Parabuthus - are known for their strong venom neurotoxins (19). Mesobuthus eupeus is found in the Middle East and Central Asia and is responsible for a large number of envenomations in these regions (19, 20).

Identification and purification of toxins from scorpion venoms may be useful tool for functional mapping of receptor sites and channel characterization. Venom purification has already been performed in Iran for identification of toxic fractions of some scorpion venoms including Odotobuthus bidentatus and M. eupeus $(6,15)$. Previously, Kadkhodaei et al. (6) isolated toxic fractions of $M$. eupeus venom through two-step purification by gel filtration chromatography with Sephadex G-50 and cation-exchange chromatography. In the present work, we extended the previous study in a new method after a three-step purification process.

In our method, the crude venom was dialyzed against deionized water for 24 hours and centrifuged for separating soluble peptides and proteins from insoluble mucoproteins. The soluble venom was applied to a Sephadex G-50 gel filtration column. The toxicity of each fraction was determined by intravenous injection into mice and each toxic fraction was further purified by two-step ion-exchange chromatography. Finally F3.1.6 and F3.1.9 were found to be the main protein components of Iranian Mesobuthus eupeus venom with cytotoxic activity. Based on the present findings, we may affirm that our purification method is suitable to obtain toxic fraction from venoms.

In order to study toxin biodistribution, the final purified toxic fractions (F3.1.6 and 
F3.1.9) were labeled with sodium pertechnetate. $99 \mathrm{mTc}$ is the most important radionuclide in nuclear medicine applications, about $80 \%$ of the radiopharmaceuticals used in clinic are based in this substance. The reasons for this central position include favorable nuclear physical characteristics and the ready availability. The halflife is short enough to enable the administration of reasonably high doses which, in turn, allow good quality images. Moreover, $99 \mathrm{mTc}$ is available from $99 \mathrm{Mo} / 99 \mathrm{mTc}$ generators in high quality and at low cost (21).

For $99 \mathrm{mTc}$ labeling, a large number of techniques have been developed and extensively reviewed (22-25). They may be classified into three main categories: direct labeling, preformed chelate approach, and indirect labeling approach $(26,27)$. The direct labeling approach usually uses a reducing agent to convert a number of disulfide linkages into free thiols, which are able to bind to $99 \mathrm{mTc}$ efficiently. It has been reported that both thiolate sulfur and imidazole nitrogen are involved in bonding to $99 \mathrm{mTc}$ (28). This method applies mostly to proteins or their fragments because of their disulfide bonds. The direct labeling method is simple and easy to perform and does not require synthetic modification nor blocking and deblocking of functional groups. We have used $\mathrm{SnCl} 2$ to reduce the disulfide bridges to provide sulfahydril groups for $99 \mathrm{mTc}$ binding. In our method, 99mTc labeled F3.1.6 and F3.1.9 with high efficiency and acceptable stability.

Biodistribution revealed that there is a high concentration of labeled F3.1.6 and F3.1.9 in kidney at one hour. The results showed that the kidneys comprise a secretion pathway of the labeled toxin. No significant accumulation in the stomach was observed, suggesting that there was no free pertechnetate in the labeled scorpion venom. In conclusion, the labeling of scorpion venom is successfully achieved with $99 \mathrm{mTc}$ using direct tin reduction procedures.

\section{CONCLUSION}

In the present studied we described an approach toward preparation and purification of a toxic fraction from the venom of Mesobuthus eupeus. Radiolabeling of the venom was performed in order to assess the most optimum conditions for labeling and potential usage in biological evaluation. Furthermore, those conjugates showed relatively good specific activity and demonstrated considerable radiochemical stability. These properties suggest that ${ }^{99 \mathrm{~m}} \mathrm{Tc}$ labeling of venom may be a useful tool for in vivo studies and is an excellent approach to follow the process of biodistribution and kinetics of toxins.

\section{COPYRIGHT \\ (C) CEVAP 2010}

\section{SUBMISSION STATUS}

Received: July 13, 2010.

Accepted: September 15, 2010.

Abstract published online: September 21, 2010. Full paper published online: November 30, 2010.

\section{CONFLICTS OF INTEREST}

There is no conflict.

\section{CORRESPONDENCE TO}

SEYED PEZHMAN SHIRMARDI, Valiasr St, Faculty of Nuclear Engineering and Physics, Amirkabir University of Technology, Tehran, Iran. Phone: +98219126864850. Fax: +982188221105. Email: p_shirmardi@aut.ac.ir.

\section{REFERENCES}

1. Zayerzadeh E, Koohi MK, Zare Mirakabadi A, Purkabireh M, Kassaaian SE, Rabbani SH, et al. Cardiopulmonary complications induced by Iranian Mesobuthus eupeus scorpion venom in anesthetized rabbits. J Venom Anim Toxins incl Trop Dis. 2010;16(1):46-59.

2. Dehghani R, Dinparast Djadid N, Shahbazzadeh D, Bigdelli S. Introducing Compsobuthus matthiesseni (Birula, 1905) scorpion as one of the major stinging scorpions in Khuzestan, Iran. Toxicon. 2009;54(3):2725 .

3. Ozkan O, Carhan A. The neutralizing capacity of Androctonus crassicauda antivenom against Mesobuthus eupeus scorpion venom. Toxicon. 2008;52(2):375-9.

4. Pipelzadeh AJ, Taraz M, Pourabbas R, Zaremirakabadi A. An epidemiological and a clinical study on scorpionism by the Iranian scorpion Hemiscorpius lepturus. Toxicon. 2007;50(7):984-92.

5. Shahbazzadeh D, Amirkhani A, Dinparast Djadid N, Bigdeli S, Akbari A. Epidemiological and clinical survey of scorpionism in Khuzestan province, Iran (2003). Toxicon. 2009;53(4):454-9.

6. Kadkhodaei Elyaderani M, Hanifi H, Amozegari Z. Isolaion and purification of toxic fractions from the venom of Mesobuthus eupeus. Urmia Med J. 2007;17(4):289-97.

7. Wudayagiri R, Inceoglu B, Herrmann R, Derbel $\mathrm{M}$, Choudary PV, Hammock BD. Isolation and 
characterization of a novel lepidopteran-selective toxin from the venom of South Indian red scorpion, Mesobuthus tamulus. BMC Biochem. 2001;2:16.

8. Matsushita N, Miyashita M, Sakai A, Nakagawa Y, Miyagawa H. Purification and characterization of a novel short-chain insecticidal toxin with two disulfide bridges from the venom of the scorpion Liocheles australasiae. Toxicon. 2007;50(6):861-7.

9. Fu YJ, Yin LT, Wang W, Chai B, Liang A. Synthesis, expression and purification of a type of chlorotoxinlike peptide from the scorpion, Buthus martensit Karsch, and its acute toxicity analysis. Biotechnol Lett. 2005;27(20):1597-603.

10. Deshane J, Garner C, Sontheimer H. Chlorotoxin inhibits glioma cell invasion via matrix metalloproteinase-2. J Biol Chem. 2003;278(6):7413544.

11. Shen S, Khazaeli MB, Yancey Gillespie G, Alvarez VL. Radiation dosimetry of 131I-chlorotoxin for targeted radiotherapy in glioma-bearing mice. J Neurooncol. 2005;71(2):113-9.

12. Huys I, Waelkens E, Tytgat J. Structure-function study of a chlorotoxin-chimer and its activity on Kv1.3 channels. J Chromatogr B Analyt Technol Biomed Life Sci. 2004;803(1):67-73.

13. Banerjee S, Pillai MR, Ramamoorthy N. Evolution of Tc-99m in diagnostic radiopharmaceuticals. Semin Nucl Med. 2001;31(4):260-77.

14. Pujatti PB, Rodrigues CJ, Gouvêa RS. Preparation of Crotalus venom radiolabeled with ${ }^{99 \mathrm{~m}} \mathrm{Tc}$ as a tool for biodistribution study. Braz Arch Biol Technol. 2005;48:9-12.

15. Masihipour B, Zare AM, Navidpour SH, Taghavi Moghadam A, Akbari A, Rabiei H. Identification and purification of the three toxins from Odotobuthus bidentatus, Lourenço and Pezier 2002, venom (Scorpiones: Buthidae). J Biol Sci. 2009;9:494-8.

16. Soprani J, Pujatti JB, Figueiredo SD, Simal C, Santos RJ. ${ }^{99 m}$ Tc radiolabeling and biodistribution study of scorpionfish (Scorpaena plumieri) venom in Swiss mice. Iran J Nucl Med. 2010;18(1):37-44
17. Murugesan S, Radha Krishna Murthy K, Noronha OPD, Samuel AM. Tc 99m - scorpion venom: labeling, biodistribution and imaging. J Venom Anim Toxins. 1999;5(1):35-46.

18. Fet V, Gantenbein B, Gromov AV, Lowe G, Lourenço WR. The first molecular phylogeny of Buthidae (Scorpiones). Euscorpius. 2003;4:1-12.

19. Sadeghian H. Transient ophtalmoplegia following envenomation by the scorpion Mesobuthus eupeus. Neurology. 2003;60(2):346-7.

20. Karatas A. Mesobuthus eupeus (C. L. Koch, 1839) (Scorpiones: Buthidae) in Turkey. Euscorpius. 2003;7:1-6.

21. Heppeler A, Froidevaux S, Eberle AN, Maecke HR. Receptor targeting for tumor localization and therapy with radiopeptides. Curr Med Chem. 2000;7(9):97194.

22. Eckelman WC, Paik CH, Steigman J. Three approaches to radiolabeling antibodies with ${ }^{99 \mathrm{~m}} \mathrm{Tc}$. Int J Rad Appl Instrum B. 1998;16(2):171-6.

23. Hnatowich DJ. Antibody radiolabeling, problems and promises. Int J Rad Appl Instrum B. 1990;17(1):49-55.

24. Hnatowich DJ. Recent developments in radiolabeling of antibodies with Iodine, Indium, and Technetium. Semin Nucl Med. 1990;20(1):80-91.

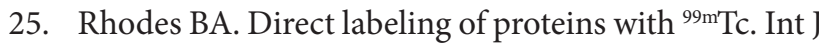
Rad Appl Instrum B. 1991;18(7):667-76.

26. Liu S, Edwards DS, Barret J A. ${ }^{99 \mathrm{~m} T c}$ labeling of highly potent small peptides. Bioconjug Chem. 1997;8(5):621-36.

27. Gandomkar M, Najafi R, Sadat Ebrahimi SE, Shafiee A, Babaei MH, Rabbani $\mathrm{M}$ et al. Direct labelling of octreotide with ${ }^{99 \mathrm{~m}} \mathrm{Tc}$ : effect of different concentration of reducing agents and amount of sodium pertechnetate on radiolabelling efficiency. Appl Radiat Isot. 2003;58(3):361-4.

28. Zamora PO, Rhodes BA. Imidazoles as well as thiolates in proteins bind Technetium-99m. Bioconjug Chem. 1992;3(6):493-8. 